\title{
IMPROVING THE NAUTICAL ACCESS TO ZEEBRUGGE HARBOR: A MULTIDISCIPLINARY STUDY
}

\author{
Chantal Martens ${ }^{1}$, Rosalia Delgado ${ }^{2}$, Hadewych Verhaeghe ${ }^{1}$, Toon \\ Verwaest ${ }^{2}$, Marc Willems ${ }^{2}$
}

\begin{abstract}
A multidisciplinary study was set up to tackle the nautical problems faced by Zeebrugge Harbor by the Maritime Access Division of the Flemish Community. The problem is twofold: strong cross-currents at the harbor mouth hinder the entrance of the ships around high water, and the occurrence of thick muddy layers hinders the navigation in the harbor and causes very high dredging costs. The article focuses on the global project set up, and explains more in detail the numerical and physical modeling research.
\end{abstract}

Keywords: harbor access, numerical modeling, physical modeling

\section{INTRODUCTION}

The port of Zeebrugge is located in the Belgian part of the North Sea Coast, in the southern bight of the North Sea. The area is shallow, with water depths averaging 20 meters and is characterized by a series of tidal sandbanks. The tidal regime is semi-diurnal with a range of $4 \mathrm{~m}$ at Zeebrugge making it

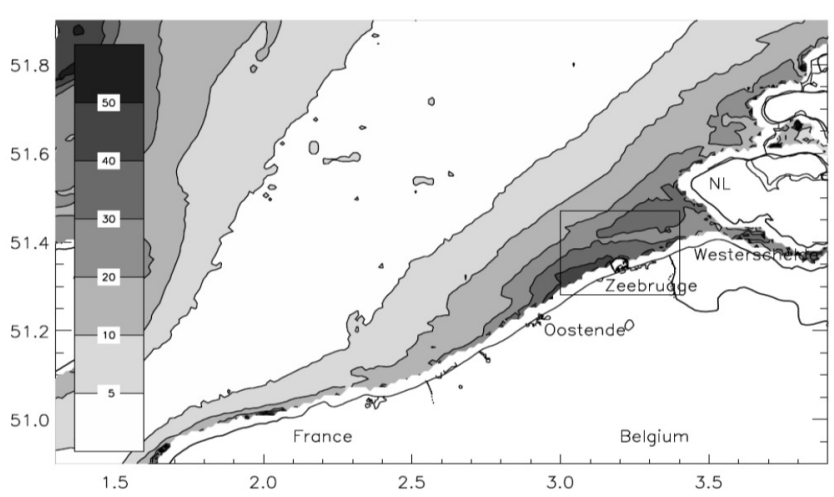

Figure 1 suspended sediment concentrations in the Belgian Coastal zone (Fettweis et al, 2010) range between 20-70 $\mathrm{mg} / 1$ and can reach values of up to $100-3000$ r 2010). The harbor of Zeebrugge is located almost exactly in the center of this turbidity maximum.

The first harbor was constructed in Zeebrugge in 1900. Between 1970 and 1985 the harbor was extended seaward. The seaward extension, protected by two four-kilometer long breakwaters gave the harbor its current shape, making it one of the major European ports. The open water surface of the harbor is now $6 * 10 \mathrm{e}^{6} \mathrm{~m}^{2}$, the tidal volume is $24 * 10 \mathrm{e} 6 \mathrm{~m}^{3}$ and the harbor mouth cross-section is approximately $12.000 \mathrm{~m}^{2}$. A $500 \mathrm{~m}$ length lock connects the outer port with the non-tidal inner port. An access channel, the "Pas van "t Zand", connects the harbor to the deepwater access channel Scheur.

The port of Zeebrugge is a multi-purpose port: it serves as a RoRo traffic port, as well as a hub port for the auto industry, a container port, LNG and other energy products up to conventional cargo and ferry services. It is the most important harbor in Europe for Ro Ro traffic and the most important harbor worldwide for the import and export of cars totaling 2 million units in 2008. Zeebrugge is also the fastest growing harbor in Europe: in 2010 the total cargo throughput in the port of Zeebrugge grew by 11 per cent to a volume of 49.8 million tons.

\section{CURRENT VERSUS FUTURE ACCESSIBILITY AND CHALLENGES FACED}

The most recent capital dredging works undertaken in 2006 and 2009 have ensured that ships with a draught up to $14 \mathrm{~m}$ have tide-independent access to the harbor. Ships with a draught up to $16 \mathrm{~m}$ have access during a tidal window of 8 to $10 \mathrm{~h}$ per day.

There are, however, additional safety restrictions that apply for ships larger than $200 \mathrm{~m}$ and for LNG carriers, reducing the effective tidal window to 4 to 6 hours per day. If the current and future

\footnotetext{
${ }^{1}$ Ministry of the Flemish Community, Maritime Access Division, Tavernierkaai 3, B2000 Antwerp, Belgium

${ }^{2}$ Ministry of the Flemish Community, Flanders Hydraulics Research , Berchemlei 115, B2140 Antwerp, Belgium
} 
accessibility - taking into account the ever-increasing ship size- is to be guaranteed, two challenges are faced.

\section{First challenge: reducing the cross-currents}

A first challenge are the strong cross-currents that occur in front of the harbor entrance. As can be seen in figure 2 , the 4 kilometers long breakwaters cause a flow contraction at the harbor mouth. The simulation shown in figure 2 shows the period of maximum flood, but a similar pattern occurs during maximum ebb. Because only the bigger ships that are entering around high water experience negative effects, the research is mostly focused on the flood period.

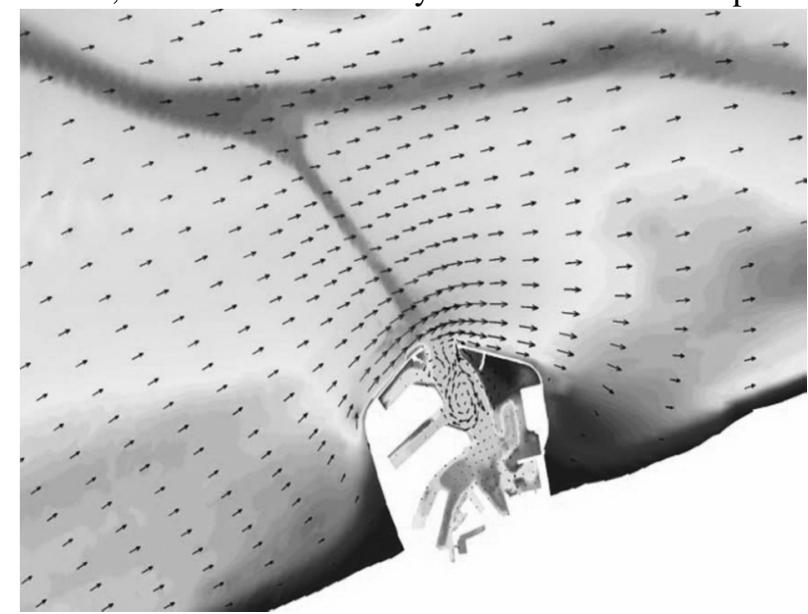

Figure 2 Flow vector during maximum flood around the harbor of Zeebrugge, from a numerical simulation (Ides et al, 2009)

\section{Second Challenge: keeping the dredging costs under control}

Since the expansion of the port between 1970-1985 and the following capital dredging works to increase the tide -independent accessibility of the harbor, thick mud layers have formed in the access channels and in the harbor itself. In order to keep the harbor navigable, a nautical bottom was defined. The nautical bottom is defined by PIANC (International Navigation Association) as "the level where the physical characteristics reach a critical limit beyond which contact with a ship's keel causes either damage or unacceptable effects on controllability and maneuverability". For reasons of survey

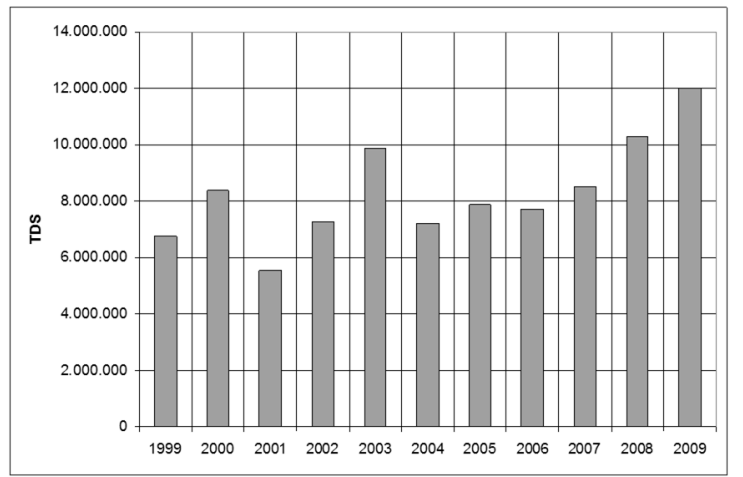

Figure 3 evolution of dredged material on the BCS in tons dry matter for 1999-2009 technology, the density of the mud is used to determine this critical limit, and based on experimental research; a density level of 1200 $\mathrm{kg} / \mathrm{m}^{3}$ was set as the nautical bottom. In addition to the $1200 \mathrm{~kg} / \mathrm{m}^{3}$ density criterion, a keel clearance of $10 \%$ with respect to the nautical bottom and a maximum intrusion of the ship's keel of $7 \%$ in mud layer were also defined (Delefortrie et al., 2007). The upper boundary of the mud layer is defined as the $210 \mathrm{KHz}$ reflection. Because the mud layers inside the harbor are reaching thicknesses of 3 to 5 meters, the effective limiting factor is not the 1200 $\mathrm{kg} / \mathrm{m}^{3}$ density level, but the depth of the 210 $\mathrm{KHz}$ reflector. Quasi-continuous dredging is required in order to keep the upper boundary of the mud layer low enough as to not interfere with the 7 $\%$ intrusion rule. Figure 3 shows the evolution of the amount of material dredged in the Belgian North Sea for the period 1999-2009. Approximately $80 \%$ of the maintenance dredging takes places in the direct access channel to the harbor of Zeebrugge, and in the harbor itself. The dredged material outside the harbor consists of $70-85 \%$ mud, in the harbor the mud content amounts to $95 \%$. With future deepening works, the dredged amount is expected to increase to keep the upper boundary of the mud layer at an acceptable depth. 


\section{RESEARCH TOOLS}

Two research paths were defined: a first path to investigate new methods for a safe and tideindependent nautical access, and a second one to study the reduction of the mud intrusion in the harbor, reducing the dredging costs. A multidisciplinary study was set up to deal with these two research paths jointly. The goal of the study is to propose one or more adaptations to the harbor configuration and/or entrance that will be beneficial for both challenges. Most likely, the final solution will consist of a combination of adaptations.

Because a broad spectrum of solutions, ranging from constructing smaller scale dams, to changes in the orientation of the harbor mouth are to be studied, two custom-made research tools were set up for this study. A combination of numerical and physical modeling will allow to adapt the research methodology in an optimal way for each of the individual scenarios being studied.

\section{Numerical model}

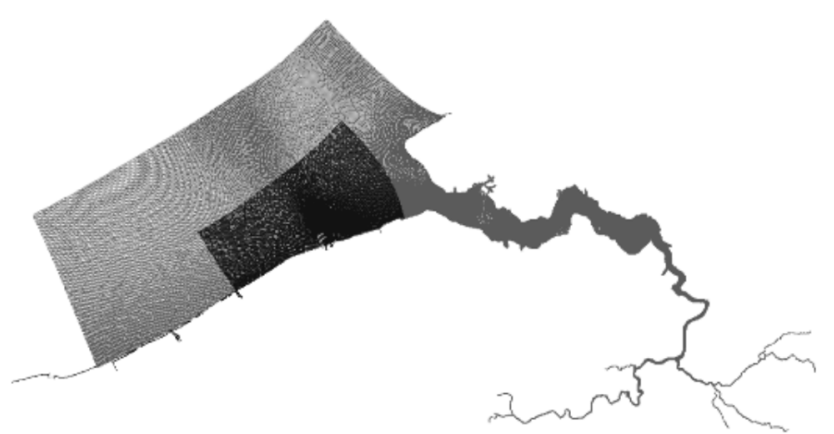

The numerical hydrodynamic model was set up at Flanders Hydraulics Research based on an existing Delft3D model of the area (Bijlsma, 2006) which was further adapted for the current research project (Dujardin et al., 2010). The model grid is shown in figure 4 . It is a 3D model with 6 sigma layers. The model area covers a bigger area than the physical model, running from Ostend to Nieuwvliet past the Belgian-Dutch border

Figure 4 numerical model grid (black) together with the LTV over a distance of approx. 40 model grid (grey). (Dujardin et al , 2010)

kilometers, the seaward boundary extending $18.5 \mathrm{~km}$ northward. The boundary conditions of the model are derived from the larger LTV model (Vanlede et al., 2008), shown in figure 4. The spatial resolution of the grid is around 30 meters around the harbor entrance, increasing towards 200 meter in the more offshore areas. Salinity and the effects of waves are not taken into account.

\section{Physical model.}

A scale tidal model of the harbor of Zeebrugge and its surroundings with a distorted scaled ratio of 1:300 for the length and 1:100 for the depth was constructed in Flanders Hydraulics (Willems et al., 2011). The physical model will mainly be used to study

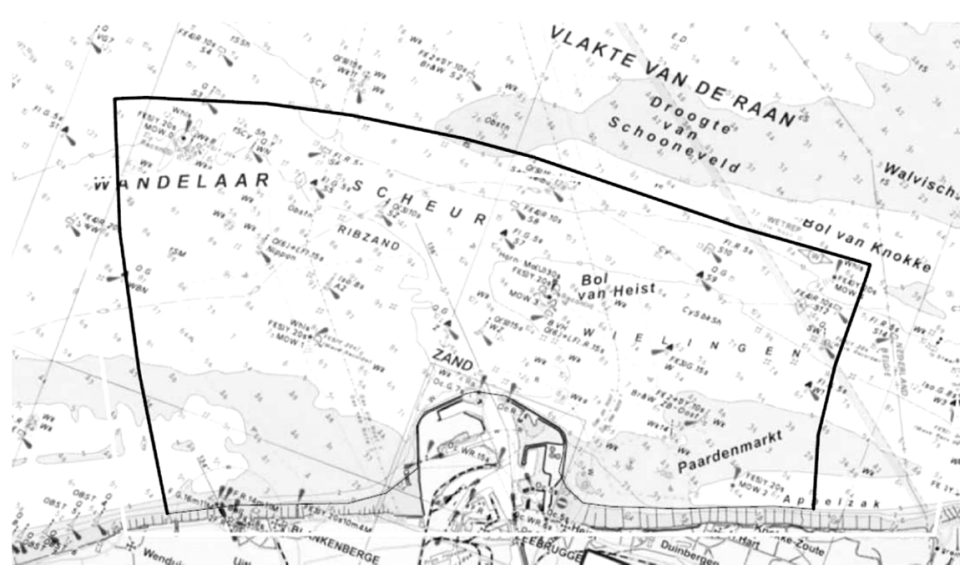

Figure 5 boundary locations for the physical model relatively small infrastructural measures around the harbor entrance. The model runs from the Belgian location of Wenduine to the BelgianDutch border, over a total length of $15 \mathrm{~km}$ in nature. The seaward boundary is located at $6 \mathrm{~km}$ offshore. The boundary locations for the physical model are shown in figure 5 .

The numerical model was used to calculate the required boundary limits for the scale model. The

boundary locations were chosen so that they were located outside the area where the hydrodynamics are influenced by the harbor structures, but still at a distance where the original boundary conditions were valid (Ides et al., 2009). The model is built with three open boundaries, at the eastern, western and northern side. The exact location of the model boundaries was set to ensure that the main flow 
direction was perpendicular to the boundary (for the $\mathrm{E}$ and $\mathrm{W}$ boundaries), or parallel to the boundary (for the northern seaward boundary).

At the eastern and western boundary of the model, pumps with fixed discharges are constructed, with a maximum capacity of $400 \mathrm{l} / \mathrm{s}$. The required discharge at a given moment in time is sent towards the model, the surplus is derived to a water reservoir. To reduce fluctuations during inflow, the water is first pumped into a parallel tank, from where it gradually enters the scale model. The downstream discharge of the water from the model is not pumped away but flows over a series of 7 (eastern boundary) and 11 (western boundary) adjustable valves. During the tidal cycle each of these valves can be controlled individually.

Along the northern seaward boundary of the model, where currents are mostly running parallel to the boundary, a flow conducting structure is placed along the boundary of the physical model. To simulate the non-parallel flow along the boundary, a discharge supply and draining system with a maximum capacity of $300 \mathrm{l} / \mathrm{s}$, coupled with a damping installation allows for a tranquil in- and outflow.

\section{Ship maneuvering simulator.}

The effects on the nautical accessibility of the new harbor configurations will be tested by a ship maneuvering simulator of Flanders Hydraulics Research. The velocity flow fields that are derived from the numerical and physical model simulations are used as an input for the mathematical model of the simulator, who then is able to evaluate the effects of the ships movement on the flow field and vice versa. This way, a very realistic simulation is created of the ships' journey.

Two types of simulations will be used to assess the scenarios. Fast-time simulations, which are simulations that are carried out by an autopilot, without human interference are used as a first assessment of the scenarios. Real-time simulation, where pilots and experienced navigators will participate will be used for the evaluation of the final scenarios. For each scenario various ship types will be tested, both for entering and leaving the harbor.

\section{PHYSICAL CHARACTERISTICS OF THE HARBOR ENVIRONMENT}

In 2006 and 2007 an extensive year-long measurement campaign was carried out around the harbor entrance. Both long term measurements on fixed locations for the time-dependant variations of salinity, sediment transport and currents, as well as through tide measurements designed for a better understanding of the current patterns and salinity and sediment distributions in de harbor and the access channels were carried out. Analysis of the measurement results, coupled with the outcome of numerical model simulations gave a good understanding of the major processes that are governing the hydro- and sediment dynamics around the harbor entrance (Dujardin, 2009). A geometrical method was used to determine three components of the water exchange. These components can give an indication of the relative importance of the different types of processes.

Tidal filling is the principal hydrodynamic component for Zeebrugge harbor. The percentage is depending on the spring-neap tide phase and the occurrence of fresh water discharges, but the average value, based on the geometrical method is around $45 \%$.

The horizontal water exchange is the water exchange through the harbor mouth because of a horizontal gradient in the flow field (for example because of an eddy formation). The net -effect is zero because the inflow equals the outflow. The calculated horizontal water exchange component can be responsible for up to $50 \%$ around maximum flood.

Salinity gradients are mostly small, and also the calculated vertical exchange is relatively unimportant (around $5 \%$ ). When however an important freshwater discharge is occurring, this number may increase and the vertical exchange can be responsible for up to $60 \%$. The percentages given for the water exchange cannot be directly translated to sedimentation - vertical exchange, for example, can be relatively unimportant for the water exchange, but could still carry a significant amount of sediment into the harbor.

Analysis of through tide measurements shows however that tidal filling and horizontal exchange process, under the form of eddies are the most significant factors for sediment import in the harbor. Around $70 \%$ of the total sediment import occurs around HW, where an eddy is formed in the eastern part of the harbor entrance. Density currents account for around 2-4\% of the total sediment import. The sediment concentrations and flow velocities at the moments where density currents are active are not large enough to cause a significant sediment import; which leads to conclude that vertical exchange processes have a negligible impact. The trapping efficiency of the harbor is calculated at $40-70 \%$, 
which means that more than half of the sediment that comes into the harbor will settle and consequently need to be dredged out.

The main conclusion from the measurement campaigns is that is expected that reducing the eddy formation will have a beneficial impact on the sedimentation in the harbor.

\section{METHODOLOGY}

As mentioned in previous sections, the scope of the study is to find a solution for both the problem of the strong cross-currents that occur around high water, and the sediment import into the harbor. In a first phase of the study, only the technical aspects are studied, later on the socio-economic aspects will be taken into account.

Other research projects are also starting up and are running parallel to this project, such as specific research dealing with the possible definitions for the nautical depth through rheological parameters or optimization of operational dredging and dumping procedures. The Flemish Coast Vlaamse Baaien development (Van Damme, 2012), providing a Masterplan with a broader framework for future developments on the entire Belgian Coast until 2050 is also connected to this study set up.

The initial scenarios are developed on a conceptual level. For each one of the concepts, a decision is made beforehand over whether they will be assessed with the numerical model, the physical model or a combination of both. The results of the first simulation will then be further refined through subsequent steps until it is clear whether a concept could be successful on its own or in combination with other measures. Also the defining parameters of the potential successful concept will be determined. Fast time nautical simulation can also be brought in at this first stage, but only scenarios that are considered successful will be assessed through real time nautical simulation.

\section{Scenarios}

Based on the conclusions of a series of expert meetings and workshops, a series of "starting point" concept scenarios were drawn. These covered a broad spectrum of possibilities, from small-scale interventions to large scale extensions of the harbor, over morphological interventions in the vicinity of the harbor. The chosen scenarios are described hereunder.

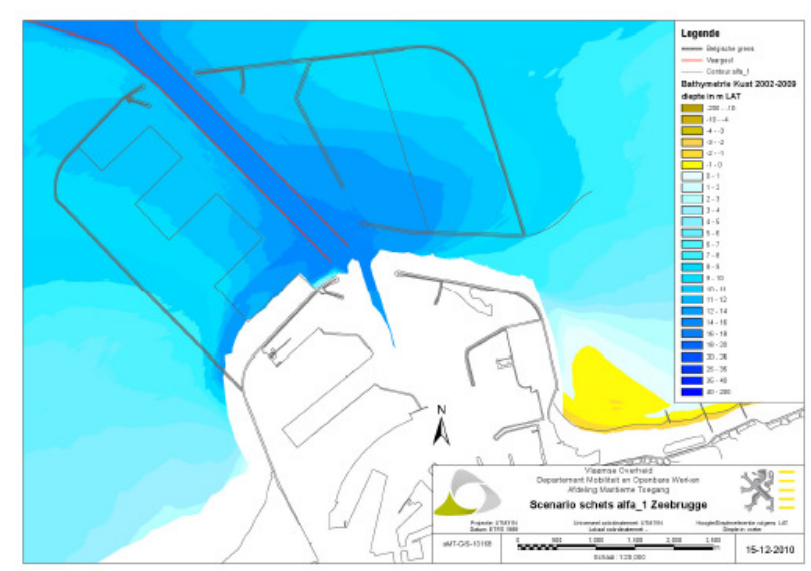

Figure 6 alfa scenario

cross-currents experienced by the ships.

Beta. The Beta scenario differs from the alfa scenario in the constructed dams being submerged. In the starting point scenario, the dam configuration is comparable to the alfa scenario. In alternative versions, the dimensions of the dams will be changed. The dams are expected to direct the eddy outward of the harbor and thus reduce the siltation. As with the alfa scenario, an increase in the cross- current is expected in front of the newer dams. The area between the new dams will offer a calmer zone. As
Alfa. The alfa scenario consists of the seaward extension of the nonsubmergible harbor dams, coupled with a harbor development. An additional exit towards the Eastern side will provide extra harbor circulation to reduce the siltation in the harbor. Although the cross current in front of the new, more seaward located harbor entrance will clearly increase if no other measures are taken, a solution can be found in locating the berthing locations for the larger ships further into the harbor, thus decreasing the gradient in the

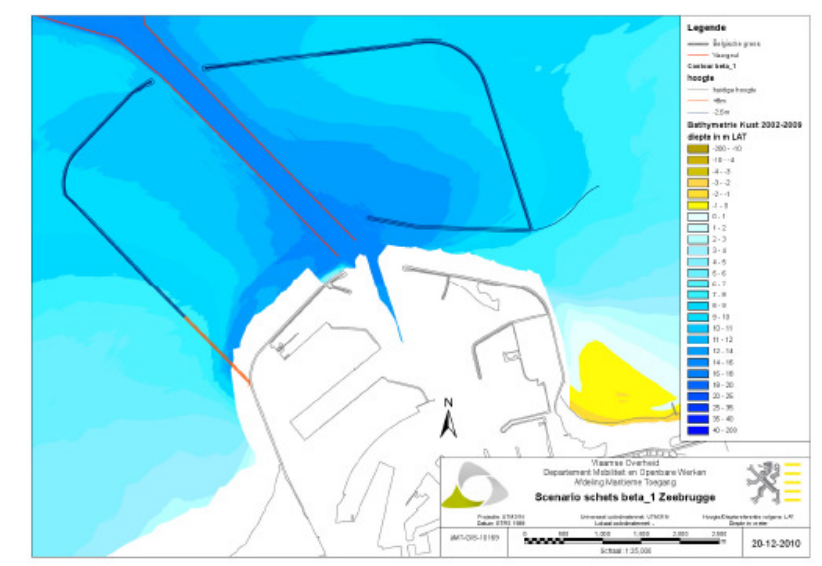

Figure 7 beta scenario 
such, the transition between maximal and minimal cross current will be more gradual. In addition to the effect on the current it is expected that the dams will also block the lower, more sediment-laden water layers.

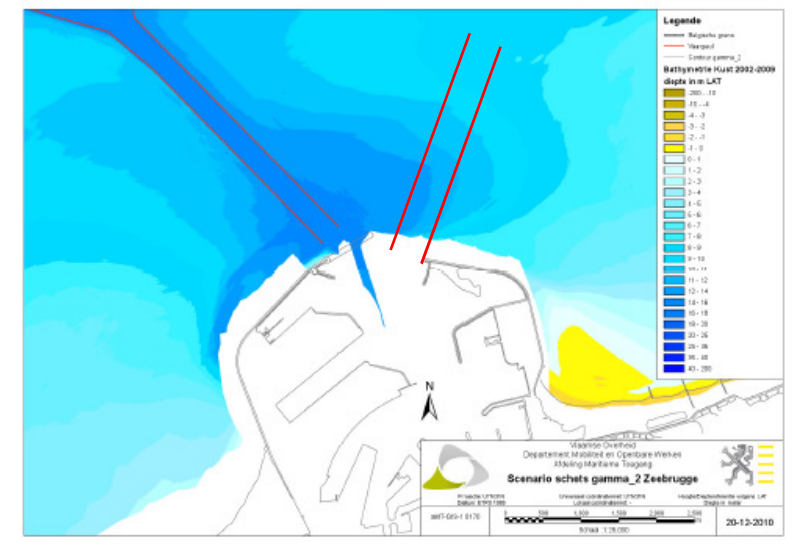

Figure 8 gamma scenario
Gamma. The gamma scenario concerns a repositioning of the harbor entrance to the North East and is a small to medium sized infrastructural change. The western harbor dam is lengthened, and the eastern dam is shortened to create a new harbor entrance. This scenario may be possibly combined with the one or two smaller submerged dams to guide the ebb stream. The change in the current pattern in front of the harbor is expected to affect the eddy formation in the harbor entrance. At the same time, a change in the shape of the harbor entrance could be beneficial to reduce the cross currents in front of the harbor mouth. This scenario also includes a change in orientation of the access channel .

Delta. A submerged coastparallel dam over a longer distance (approx $15 \mathrm{~km}$ ) is expected to have a positive effect on the flood contraction in front of the harbor entrance.

Epsilon. The creation of an artificial island is expected to influence the current distribution in the access channel to the harbor, and the cross current gradient. Attention must be given to the shape and location of the island, as it is expected that the current northwards and southwards of the island will increase, which may lead to an increase in the cross current in front of the harbor. Possible alternatives include a non-submerged and a submerged island,

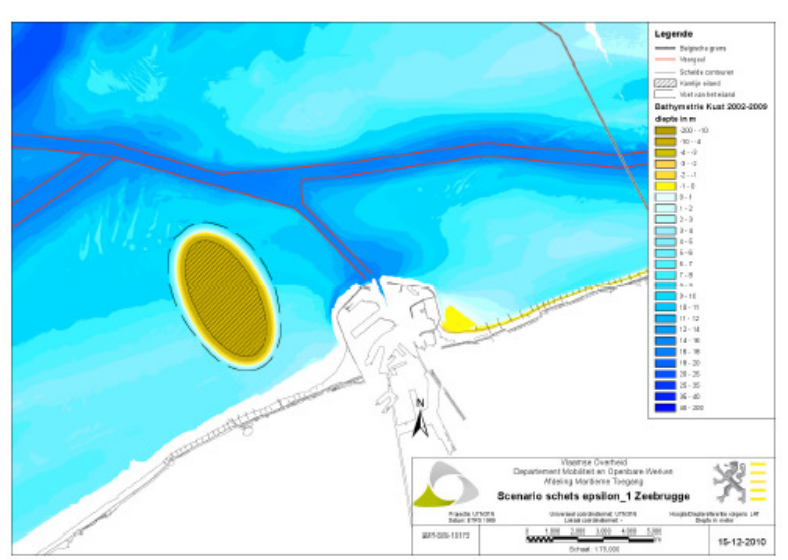

Figure 10 epsilon scenario

channel.

Eta. The effect of constructing a series of smaller dams (submerged or not submerged) at an angle to the existing beach is comparable to the zeta scenario. The series of dams offer more flexibility compared to the construction of a new beach above MLW. The area influenced is expected to be comparable to the zeta scenario. the former opening possibilities for synergies with for instance recreation or creation of nature reserves.

Zeta. The problem of the high crosscurrents at the harbor entrance is caused by the sudden contraction of the flow lines in the area to the west of Zeebrugge. Broadening the beach (defined as the area above the mean low water level) in this area (with the new beach attached to the harbor on the Western side) is expected to the contraction more gradual, causing a reduction in the cross-current or in the cross-current gradient in the access 
Theta. The theta scenario consists in the creation of a zone with increased roughness. The location and area of this zone needs to be determined, as well as the increase in roughness required to obtain a significant effect. A possible way to attain the necessary roughness could be by placing a tidal turbine farm to the West of the harbor area, as the tidal farm will decelerate the flow and generate energy at the same time. A first research has shown that a significant increase in the accessibility could be obtained this way (Duchatelet, 2012). An attention point with this scenario is the configuration of the tidal farm, as the flow between the zone with increased

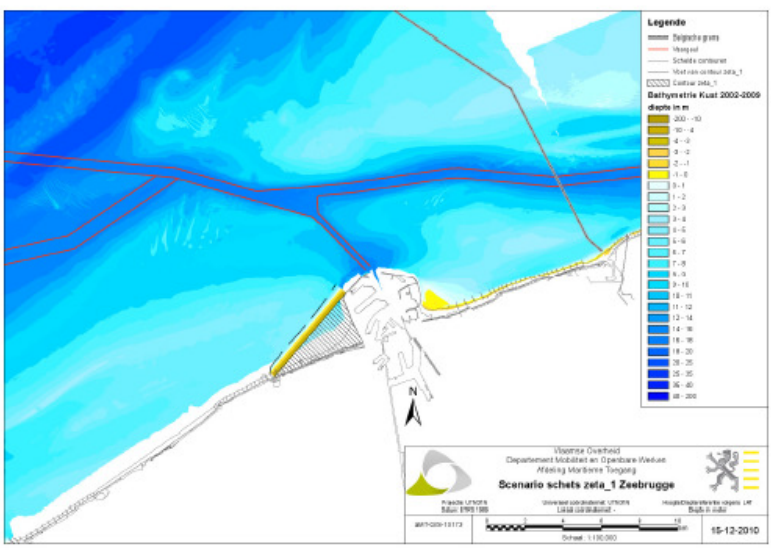

Figure 11 zeta scenario

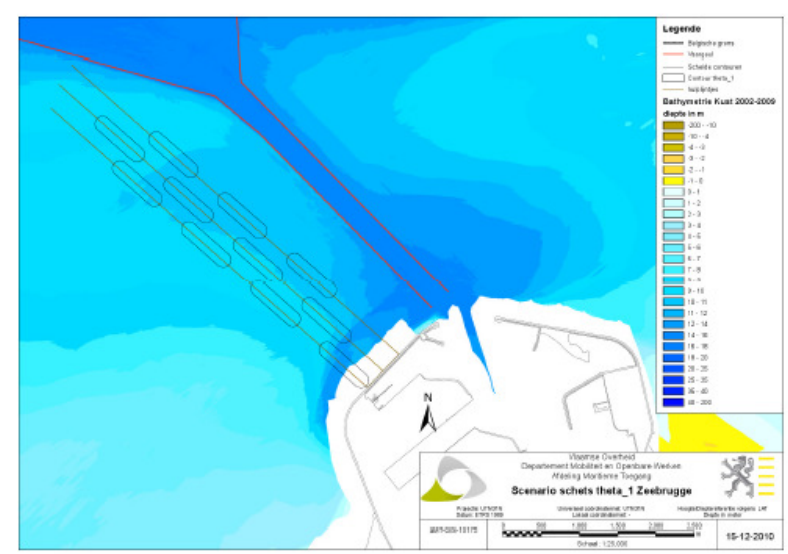

roughness and the western harbor dam could still cause an increase in the crosscurrent in the access channel.

\section{Figure 12 theta scenario}

\section{Indicators and processing of the results}

Indicators were defined at the beginning of the project in order to assess the results of the simulations and to compare the different scenarios. A standard processing method for each of the scenarios was defined. This processing method summarizes the scenario in a series of key numbers and figures that indicate the influence of the scenario on flow velocities, water exchange and sedimentation in the harbor with respect to the reference situation. The same method is applied to a reference situation (current situation).

Flow Magnitude. In order to compare the different scenarios an overview of the maximal, depthaveraged, flow velocities that occur is given for every scenario based on maximal flood flow (figure 13) and maximal ebb flow as well as the maximal flow over the entire tidal cycle. This figure does not represent a fixed point on the tidal curve, but shows for each of the model points the maximum flow velocity that has occurred over the entire tidal cycle. For each individual point this could be during the flood phase (e.g. at the entrance channel) or also during the ebb phase (e.g. in the deepwater access channels). In order to represent the $3 \mathrm{D}$ results in a $2 \mathrm{D}$ rendition, the flow velocity was averaged over a depth of 10 meters. This is the same depth as used in the representation of flow vectors for the nautical access atlases for Zeebrugge. In addition to the values for the maximum flood, ebb and overall flow velocity; a comparison will also be made with the reference situation. 


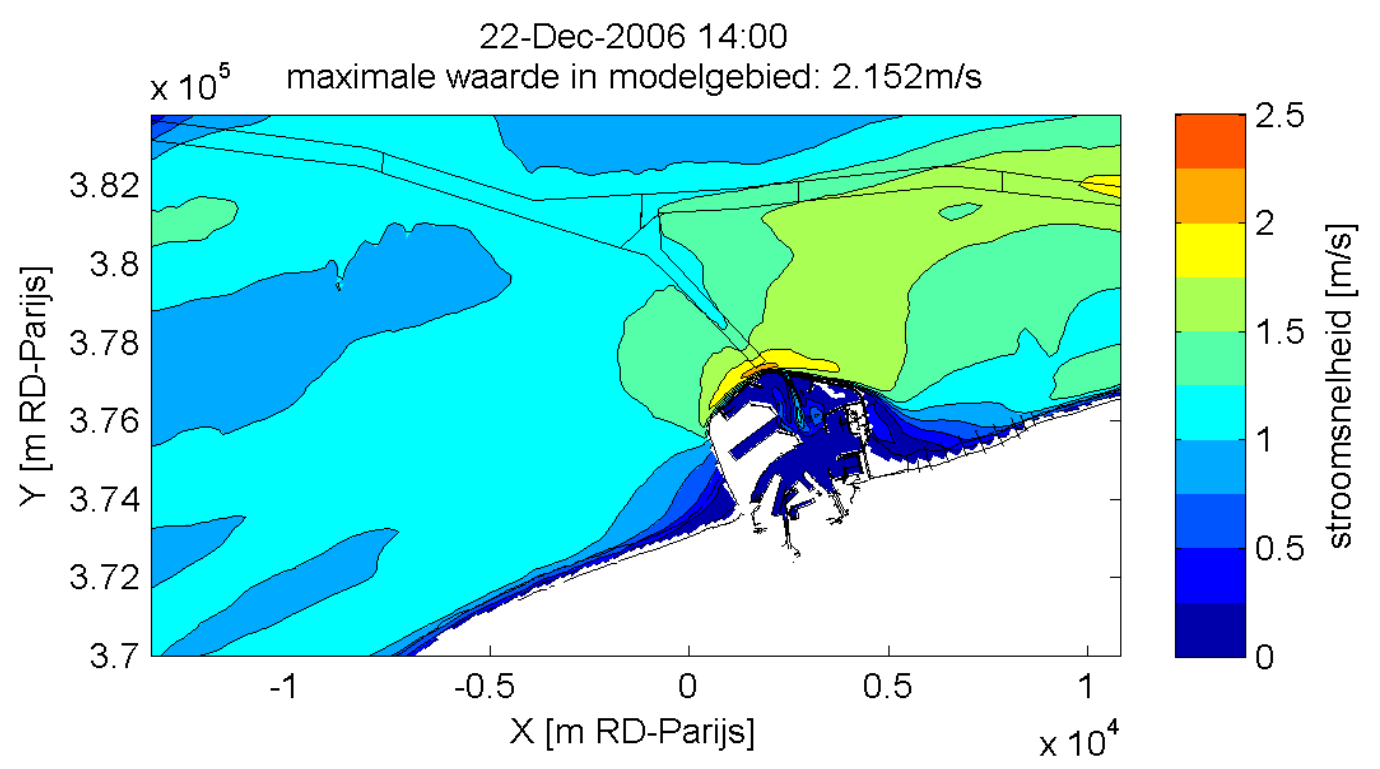

Figure 13 maximum, depth averaged flood flow (Dujardin, 2009)

Accessibility window, based on the cross current. In order to define safe accessibility of the harbor, threshold values for the cross current velocity have been defined at $1.5 \mathrm{kn}$ and $2 \mathrm{kn}$ for LNG carriers and ships larger than $200 \mathrm{~m}$ respectively.

For each scenario the accessibility window, both for the 1.5 and $2 \mathrm{kn}$ tresholds is presented against the water level curve. The red (for the $2 \mathrm{kn}$ ) and blue (for the $1.5 \mathrm{kn}$ ) strips in figure 14 indicate points in time where the cross current exceeds the threshold value in at least one point in the $7500 \mathrm{~m}$ long trajectory along the access channel. As can be seen in the figure, the cross current outside the harbor exceeds the threshold around maximum flood.
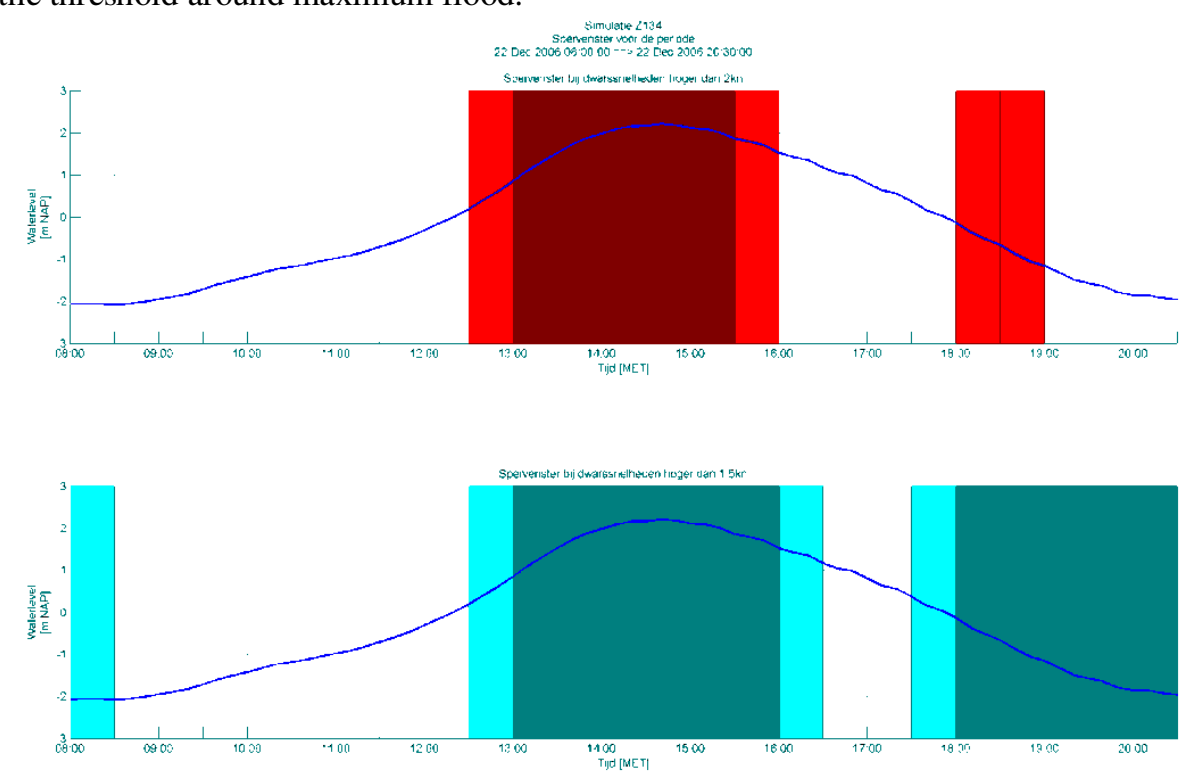

Figure 14 Accessibility window - based on the cross current (depth averaged) along the access channel to the harbor for the reference situation (Dujardin, 2009), for the $\mathbf{2}$ kn criterion (in red) and $1.5 \mathrm{kn}$ criterion (in blue)

To be able the assess the gradient of the cross current, time plots are made of the cross current in fixed points along the trajectory (figure not shown).

Water exchange at the harbor mouth. For each of the scenarios, the distribution of the water exchange at the harbor mouth over the three components, tidal filling, horizontal exchange and vertical exchange is calculated. Comparison with the reference situation allows assessing shifts in the inflow pattern, or the importance of the components, leading to changes in the sedimentation pattern. 
Detailed analysis of the cross current along the navigation route. Not only the period during which the threshold value is exceeded is important, but also the distance over which the exceedance takes place.

Figure 14 shows the exceedance of the threshold value at at least one point along the access channel to the harbor at a specific moment in time. It is also interesting to know over which distance and how long the threshold value has been exceeded, so that the significance can be assessed. In figure 15 a color scale indicates the value of the depth - averaged flow velocity perpendicular to the navigation route. An identical figure will be created for two additional transects, $125 \mathrm{~m}$ eastward and westward of the navigation route for every scenario. A comparison with the reference situation is also made in order to assess improvements.
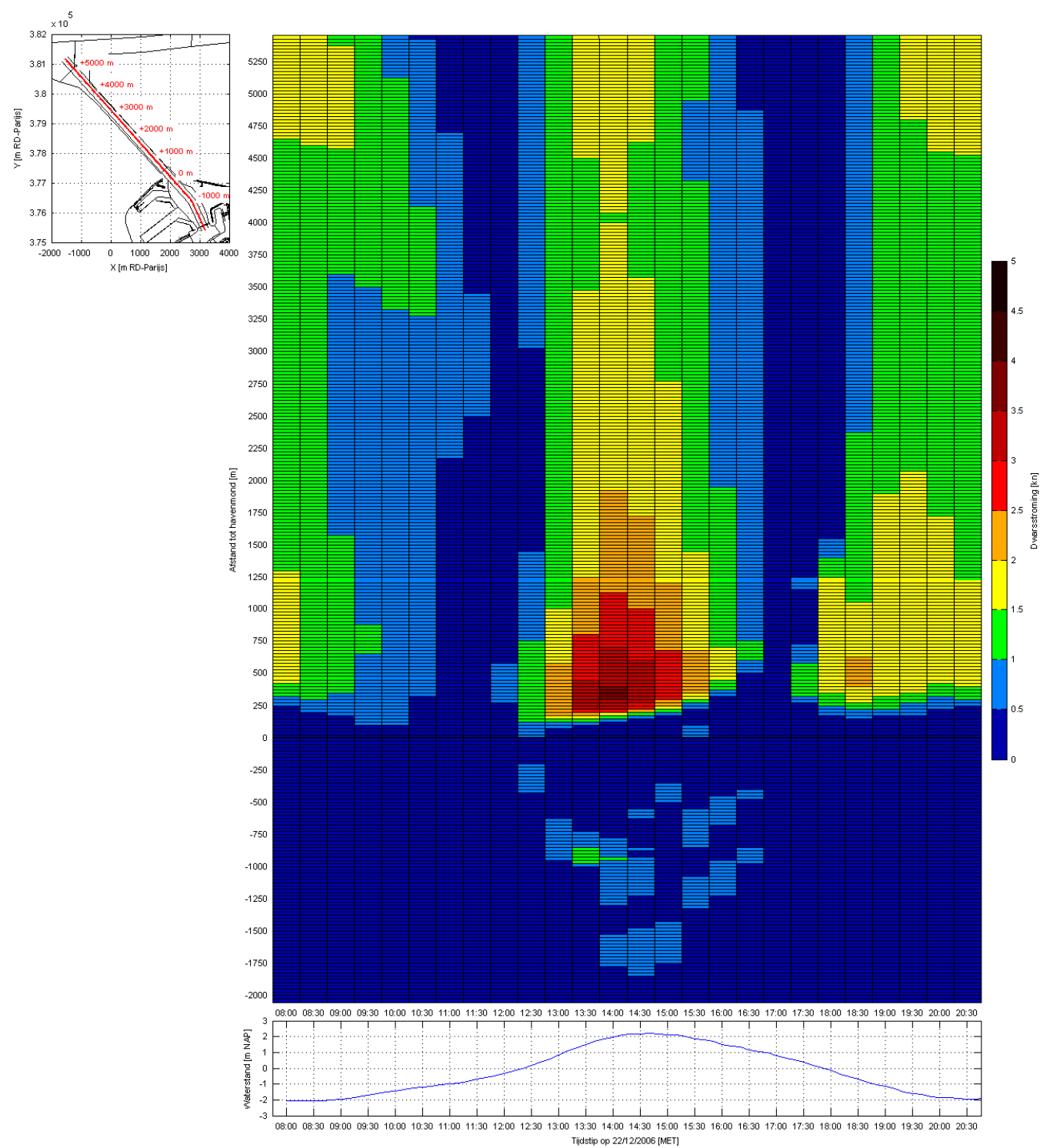

Figure 15 depth averaged cross current along the navigation route over the entire tidal cycle

\section{FUTURE RESEARCH}

The research tools (both numerical and physical models) are expected to be fully operational by November 2012. Nautical simulations will be starting shortly afterwards, based on the results of the first scenarios. First results are expected by the summer of 2013. 
Currently, an approximation based on the results of the hydrodynamic model is used for the calculation of the siltation in the harbor. A sediment transport model for the area is being set up, so in due course a more precise approximation to the sedimentation and related processes will be possible.

\section{REFERENCES}

Bijlsma, A. 2006. Memo Haven van Oostende - studie nieuwe haventoegang. Onderzoek van de HLES methodiek van Delft3D-Flow voor de haven van Zeebrugge. WLIDelft Hydraulics Delft, Nederland in opdracht van Waterbouwkundig Laboratorium Antwerpen.

Delefortrie, G., M. Vantorre, E. Verzhbitskaya, K. Seynaeve. 2007. Evaluation of safetyof navigation in muddy areas through real-time manoeuvring simulations. Journal of Waterway, Port, Coastal and Ocean Engineering. Asce 133 : (2) 125-135 MAR-APR 2007

Dujardin, A., S. Ides, G. Schramkowski, T. De Mulder, F. Mostaert. 2009. Haven van Zeebrugge optimalisatie maritieme toegankelijkheid : onderzoek naar de water - en sedimentuitwisseling ter hoogte van de havenmond. Versie 3_0. WL Rapporten, 843_01, Waterbouwkundig laboratorium Antwerpen.

Dujardin, A., B. De Clercq, J. Vanlede, R. Delgado, G. van Holland, F. Mostaert.2010 Verbetering numeriek instrumentarium Zeebrugge. Bouw en afregeling detailmodel. Versie 2_0. WL Rapporten, 753_08, Waterbouwkundig Laboratorium, Soresma en IMDC,Antwerpen, Belgie.

Dujardin, A., J. Vanlede, B. De Maerschalck, F.Mostaert. 2011. Verbetering numeriek instrumentarium Zeebrugge : deelrapport 3 - stromingsmodel met verfijnd rekenrooster voor Zeebrugge en de Pas van het Zand. Versie 2_0. WL Rapporten, 753_08. Waterbouwkundig Laboratorium, België.

Duchatelet, M. 2012. Hoe getijdenturbines de dwarsstroom te Zeebrugge reduceren. M.Sc. Thesis Gent University

Fettweis M., et al. 2010 Monitoring the effects of disposal of fine sediments from maintenance dredging on suspended particulate matter concentration in the Belgian nearshore area (southern North Sea). Mar Pollut. Bull. doi:10.1016/j.marpolbul.2010.11.002

Ides S., T. De Mulder, F. Mostaert. (2009). Optimalisatie Toegankelijkheid Zeebrugge, Onderzoeksplan WL Rapporten780_03, Waterbouwkundig Laboratorium, Antwerpen, België.

Van Damme, L. 2012. Flemish Coast- Vlaamse Baaien development plan. ICCE 2012 conference proceedings.

Vanlede J., B. Decrop, B. Declercq, S. Ides, T. De Mulder , F. Mostaert. 2008. Verbetering randvoorwaardenmodel - deelrapport 1 : gevoeligheidsanalyse. WL Rapporten 753_09 Waterbouwkundig Laboratorium \& IMDC, Antwerpen, Belgë.

Willems, M., B. Van Dingenen, R. Delgado, T. Verwaest, F. Mostaert. 2011. Nautische toegankelijkheid haven Zeebrugge : technisch ontwerp schaalmodel. Versie 2_0. WL Rapporten , 780-03. Waterbouwkundig Laboratorium, België 